\title{
The Form Explorations about the Network Reproducing of the Screen Art at “Internet +" Era
}

\author{
Jie Cai ${ }^{a}$, Yuzhen Cao \\ Nanchang Institute of Technology, Nanchang 330044, China \\ a103006664@qq.com
}

Keywords: Internet +, Screen Art, Network Reproducing

\begin{abstract}
Under the context of the China Internet rapid development, the development of screen art has been transfer from the dependency on the network transmission to the new audiovisual form which is fusion the network reproducing. The network reproducing of the screen art will generate new value, new culture, and it could derivative more new products. From the movie "Fleet of Time" to the network drama "Fleet of Time", and from the TV play "Nirvana in Fire" to its homonymic mobile game, all of these have conducted the new art form, as well as expanded the new audience. Blending the internet thinking to achieve the screen art reproducing is the objective of the screen industry development necessarily. Researching the value and form about the network reproducing of the screen art could promote the ecological development of screen industry more effectively.
\end{abstract}

\section{The thinking model of the screen art development at "Internet +" Era}

Internet + Screen Art $=$ Using Internet Thinking Model make Screen work

Primary Stage. The screen art works make Internet as a transmission channel, but its art creation process and formation is still use the traditional model. For example, "Love is not blind", "Tiny Times" and other movies using the virus-like Internet spread approach to promote movies, which provide the strong support for its box office. Another example is the TV series "Ten great III of peach blossom", which is simultaneously broadcast at Zhejiang TV, Shanghai Dragon TV, Anhui TV, as well as broadcast hotly at six network platform, including the Youku, Tencent, iQiyi, LeTV, Sohu, and PPTV. This drama creating the 2017 drama viewing climax, which is broken audience rating 1 at the each TV channel, and broken the 20 billion network VV fast at the same time. The TV variety "Brothers to run" has been ranking first at national network audience rating for consecutive four seasons from the first season.

This is only the power of the Internet as a broadcast medium.

Advanced stage. The creators of screen art could realize that using the Internet as a medium cannot achieved faster and better development of screen art industry through the conclusion of the previous stage. The popularity of the Internet, the growth of the cultural demand, and the younger audience group of the screen works, all of these makes the traditional media aware the importance of the Internet thinking. The so-called Internet thinking refers to the traditional industry integrated the user information through the Internet, understood the user demand through the establishment of big data analysis mechanism, researched and developed the new products, and completed the aftersale service system via planning the user experience way. It create new marketing methods and obtain greater profits by updated new profit channel via the Internet. Using the big data thinking strengthen the competitiveness of enterprises to achieve multi-dimensional cross-border business model. So the injection of Internet thinking make more traditional media industry realized that the Internet is an important platform for screen marketing. Network literature is a new idea of screen drama creation, watching the film on the Internet is a new way of life. In the "Internet +" ear, the traditional creation way, publicity model and art form of screen art cannot satisfied the development demand of the entire media industry, it must use the internet thinking to achieve the revolution of the screen art innovation development. 


\section{The meaning about the network reproducing of the screen art}

\subsection{The demarcation about the network reproducing of the screen art}

Reproducing means to re-create life. Extending this word to the creation of screen art, and based on the basis of the traditional screen art form, to create a new art form by guidance of Internet thinking. This new work form is not the recurrence of the original art form, it will bring a new position of the external manifestations and audience group to art work. After reproducing, the screen art works could generate more new artistic value and economic value, and will also expand the new customer base to support the ecological development of its industrial chain.

\subsection{The network reproducing of screen art generate new value}

The main body of screen art reproducing is several of traditional screen organizations and the production and transmission platform of Internet video. And the driving force of this kind of company to achieve the screen art network producing is the economic value. A good screen work, whether box office or audience rating, is directly reflect the audience recognition and popularity intensity of this work. So that the amount of box office and audience rating is illustrated the range of this market. Based on a successful screen work to reproducing a new art form is the multi-use of one source, which is a kind of investment approach that could saving the costs and ensure the capital recovery. Not only that, Internet thinking promote the development of screen art derivatives and its sales, to achieve the "platform + content + terminal + application" of the whole industry chain service system, which has very impressive economic and social value.

Although the network reproducing of screen art is an economic behavior in form, its creative process is still a multi-level blend of the artists' thinking. Internet thinking achieve the further integration of the screen, literature, games, cartoon, variety, and entertainment information. No matter that is the TV series reproducing as the network drama, or screen drama reproducing as the mobile games or variety show, it is the recognition of the original work and it is also the enrich and sublimation to the original work. This kind of reproducing has spawned the genre types of network drama and online games, it also has spawned plenty of artists in this industry.

The screen drama pass the some kind of feelings from director and actors, it derived the virtual "success" and "perfect" desire from the audience in the reproducing works. For example, in the TV series "Nirvana in Fire", Mei Changsu, the hero of this drama, is a seriously ill but wise avenger. The handsome character image, the bootstrapping stratagem, and the helpless love to the infant, all of these bring plenty of regret to the audience. However, the mobile game could satisfy the emotional demands of audience about the plot control, plot adaptation, and extend emotion. This kind of art reproducing strengthen the emotion in works, and also make up the spirit lack of online game customer, its cultural value and social value has also been extended.

\section{The performance form about the network reproducing of screen art}

The performance form about the network reproducing of screen art mainly based on its artistic form, via the guidance of Internet thinking, and reproducing its cultural innovation essence to another online video form. In this reproducing process, the media, the audience, the art language, the business model, the profit channel, and even the social and cultural forms have changed. Screen art reproducing not only achieved the complement the advantages between the traditional media and Internet media, but also enriched the content and form of online video works, creating more social value and economic value.

\subsection{Screen drama reproducing as network drama}

The excellent screen art works not only can spread through the Internet, it also can provide fresher theme to the network drama creation. Various types of video sites can try to combine the characteristics of network culture to remake the classic screen works. In the Internet era, the value of IP (Intellectual Property) is immeasurable. Such as the TV series "Shenduan Di Renjie" reproducing as the network drama "DIRENJIE - The Famous Detective", which re-deconstruction 
the "Di Renjie" this wisdom Chinese detective image. It subversion of the past classic detective story routines, and giving the new Internet spirit on it at the same time. As well as the film "Forever Young" reproducing as the network drama "Forever Young", the film "Fleet of Time" reproducing as the network drama "Fleet of Time", both are talking about the story of youth, and filled with love and the longing for a better life. Although the visual effects of network drama is not as good as the film, its plump figure and rich emotional interpretation is as good as film. And the randomness of network drama audience rating and the compactness of plot is more fit to the audience demand of younger internet users.

The movie "The Ghouls" was released on December 26th, 2015, it broken 1 billion Yuan box office by only 8 days. This is an expedition film with strong Chinese traditional cultural connotation. Except of the Eight Diagrams, the Geomancy and other Chinese specific cultural factors, it also contain the "Gate of hell”, "danger spot”, "Higanbana” and other inherent elements in Chinese traditional thinking. This theme has now been re-created as three network drama. One of three is the "Candle in the tomb", which is the network drama starring by Jin Dong and Chen Qiaoen, which can be described as one of the most conscientious network drama in 2016. When this drama play over the half, the VV mount on the internet is closed to 1.6 billion, and the reputation is on line all the times, and it also has 8.4 point of high points on the Douban Movie. The film not only has the stunning late effects, also has the excellent actor, which is using the configuration of the TV series to take a good network drama. The other two network drama are the "The tomb of Ghost Blows out the Light" and the "Ghost blowing light Makino tricky", both will be release on July 2017. This two movie are broadcast by Tencent and iQiyi respectively, which aroused highly concern before on line. Since the film "The Ghouls" success, plenty of network video production companies pay attention to the "The Ghouls" theme. The same theme, same character design, and same feelings, are integrated the brave and fearless adventure sprit, and expressed the modern younger's desire and insistent about the love. This kind of work is not only the entertainment and pastime, but also to meet the needs of the audience by a new form of art.

\subsection{The screen drama reproducing as online game}

Reproducing the screen drama works to the online game is the new thinking of the internet video industry. In traditional thinking, some of successful screen works is reproducing by the online games. For example, the fantasy TV series "The Legend of sword and fairy" is adapted from the same name online games in 2004. After that, the "Xuanyuan sword" and the "Swords of Legends" have also received a good TV income. However, in 2012, the SARFT (The state administration of radio film and television) proposed that the online games cannot be adapted as the TV series. So that reproducing the TV series to the online game become the new direction of online game company. It is worth mentioning that the TV series "Ten great III of peach blossom", which has occupied the TV screen at the first quarter of 2017. Until March 2017, its online viewing amount reached 29 billion, which is already over the 11.57 billion viewing amount of "The mystic Nine", the first ranking of online viewing amount in 2016, far ahead of the other network drama. After the TV series broadcast, the Zhejiang Dragon Pipe Manufacturing Co., Ltd announced in the June 22, 2017 that Gashenyoutong Company signed the contract” the exclusive game R\&D and distribution agreement about 'Ten great III of peach blossom' serious" with the Chuntian entertainment, which has the game copyright of it. For example, the TV series "Romance of the Three Kingdoms", "Dragon Oath", "The magic blade", "the journey of Flower", "the legend of Miyue", "Nirvana in Fire", "the legend of Chuqiao", " Fighter of the destiny "," Missing the Beauty "and so on. As well as the film "Journey to the West", "Despicable $\mathrm{Me}$ " and other films also rewrite as the mobile causing its excellent viewing rating. It can be seen that the screen drama has a broad prospects for online games.

The idea of adapting TV series been stopped is mainly because the most of TV series which adapted by the game company are involved plenty of emprise and fantasy, lack of real cultural value. And now under the guidance of Internet thinking, it provide the good cultural value and quality assurance for the screen works reproducing as the online games. For example, the game "Romance 
of the Three Kingdoms" has important historical figures and events, and also have the integration of Chinese wisdom. Another example were the "the legend of Miyue", "Missing the beauty" and " Sima Yi" such kind of biography screen works, which are generally not as the subject of online game content. However, the charisma and historical culture shown by the character attract more internet use want to have similar cultural experience. Online games are no longer purely killing, the historical and the literary will conquer more high-level intellectual people to participate in the game. The participation, interactive and social function of online games are far greater than the audiovisual features of screen works, this art reproducing will also be a sublimation of the works of screen art from connotation to function.

\subsection{The screen drama reproducing as online story advertisement}

The distribution company of traditional screen drama has large extent dependent on the advertising to recover costs. Its advertising form is nothing more than spots and implantation. However, the screen drama has a new form of art in the fast-paced of Internet communication process, which is the story advertisement. During the broadcast process of screen drama will appear story advertisement. The characteristics of this ad is dominated by a number of supporting roles, with the same characters dress and advertising shooting scenes of drama. Audience will easy to confuse the script itself and advertising, until the appearance of advertising products. It rise the audience's attention to the advertising, and it impressed audience deeply. And the planning of the ad plot is still very humorous and interesting, to meet the many young people's aesthetic taste cleverly.

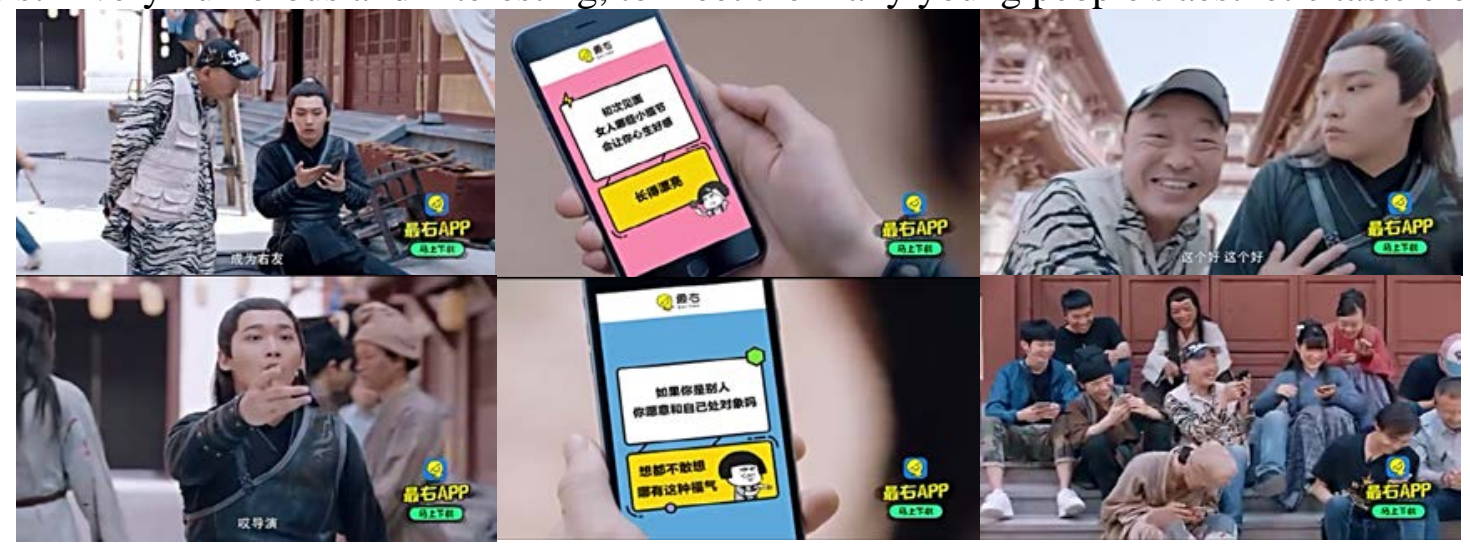

\begin{tabular}{|l|l|l|}
\hline Figure 1 & Figure 2 & Figure 3 \\
\hline Figure 4 & Figure 5 & Figure 6 \\
\hline
\end{tabular}

For example, when "the Legend of Chu Qiao" broadcast at iQiyi, it will inter-cut a story advertisement of "Right APP". The starring of advertisement is "Yue Qi", the personal guards of hero, and the advertising scene is the TV drama shooting scene. There is also a "director" act with "Yue Qi" together. Figure 1 shown that the Yue Qi introduce the "Right APP" to director. Through Figure 2, the audience can see the words on the phone screen to introduce "Right APP" is a friend software, which not only can see the funny video, and also be a happy community with plenty of funny comments. Figure 3 illustrated that the director is very satisfied with the APP. Figure 4 shown that the director grab the mobile phone from Yue Qi. Figure 5 demonstrated that there has a funny comment. Finally, the Figure 6 shown that the director playing "Right APP" with plenty of actors. This ad allows the audience to receive information unknowingly. Not only do not feel offensive, but also focus on advertising information content. Even feeling some of nonsense but also readily accepted it.

The kind of creative story advertisement rely on the existence of screen works. The actor clothing modeling, scene settings, and even the advertising copy has closely contact with the drama. Compared to the traditional spots advertising, the audience will not get out from the story, and will not produce boredom during watching. Compared with the implantation advertising, it has a stronger conduction function, more prominent advertising theme, and suitable for pre-publicity of new production. It also can meet the young Internet users' demand about seeking new and innovative entertainment on the greater extent. 


\subsection{The network reproducing about the screen art derivatives}

Each hot screen work will bring the all-round concerns of audience. The props in screen drama, even a bag, a piece of clothing, a food, an ornament, and so on, can become a derivative with more commercial value, and so that to achieve an ecosystem of the screen art development. For example, official custom-made "wine" of "the legend of Miyue" (Figure 7) to achieve 20 million Yuan sales in two months. This wine based on the LeTV ecosystem, has on-line and off-line multi-platform resources, to build scene though from the watching to purchase. There are lots of similar derivatives, such as the "Baicao taste peach blossom---memorialis hirta" in the "Ten great III of peach blossom" (Figure 8). This is the synonym product depend on the plots of drama which is specific produced for the fans. This food is given by more emotion, the slogan "the course of life, with your joy" makes it be the best selling products on Valentine's Day. As well as the sunflower pillow and "cheap cat" doll in "Love is not blind". These low price props have emerged the out of stock phenomenon.

Under the guidance of Internet thinking, the props that arranged by the director and screenwriter carefully will generate some kind of contact with the actors. It will touched the audience during the viewing and be the derivative at the same time. The preferences and purchase of derivatives by audience have proved the strong appeal of screen work itself. Therefore, the reproducing of derivatives is not focus on how good of the product itself, it focus on how to use internet better to planning the development of derivative at the same time with the creation of screen works. The little toys shown on the drama will pin of some new emotion and meaning after the discussion of the internet users.

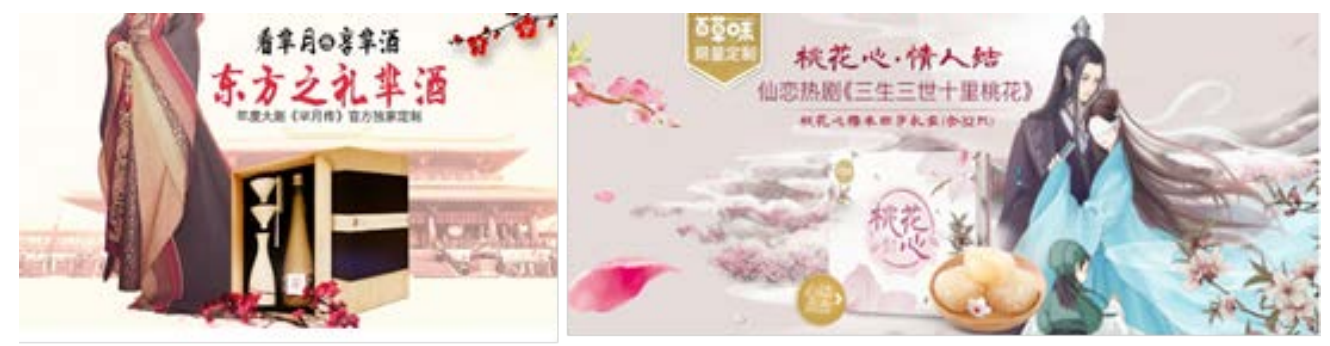

Figure 7 "Mi Wine”

Figure 8 "Baicao taste peach blossom---memorialis hirta”

\section{Conclusion}

The Internet has changed the traditional business model and marketing ideas, and also gave the screen art more social value and cultural connotation. Below the Movie "Mr. Six", the TV series "Ode to joy", online games "World of Warcraft" and other popular screen works, it is the coperformance of a number of internet companies. The cross-border cooperation of traditional media and Internet companies will burst out more exciting sparks. Screen art network reproducing is not only the research on a good IP work, it also be a revolution of the business operation model. Internet companies deeply involved in the field of screen creation, will give the screen industry disruptive changes on financing, planning, production, marketing, online publishing, derivatives production and marketing industry chain. This will become the development direction of the traditional screen industry in the future.

\section{Acknowledgements}

The Research Project of Jiangxi Higher Education Humanities and Social Sciences Project Item No. YS1569.

\section{References}

[1] Zhou Qingpin, "Movie Art”, 2016 Jan 5 $5^{\text {th }}$, the fusion and fission of modern screen art culture gene in "Internet + " modle 
[2] Lv Ying, “Industry and Science Forum”, 2015 Dec 30 ${ }^{\text {th }}$, the blend development exploration between the traditional screen art and new digital media

[3] Zhang Yue, Dalian Polytechnic University, 2016 Jun 1 ${ }^{\text {st }}$, Master thesis, Chinese IP drama features report under the new media viewpoint

[4] Shao Peiren, [G] Higher Education Press, 2006, Communication study

[5] Li Dongshen, Wang Xiaoqi, Zheng Nan, The home of Drama, 2015 Feb $8^{\text {th }}$, the conflict and fusion between traditional screen art and new digital media

[6] Tian Chenglong, Beauty and Times (Rudin), 2015 Apr. 25 $5^{\text {th }}$, the development situation of IP drama and the prospect forecast of it under the "Internet + " Era 